\title{
Essências florais: intervenção vibracional de possibilidades diagnósticas e terapêuticas*
}

\author{
FLOWER ESSENCES: VIBRATIONAL INTERVENTION OF DIAGNOSTIC AND \\ THERAPEUTIC POSSIBILITIES
}

\author{
ESENCIAS FLORALES: INTERVENCIÓN VIBRACIONAL DE POSIBILIDADES \\ DIAGNÓSTICAS Y TERAPÉUTICAS
}

\section{Olympia Maria Piedade Gimenes ${ }^{1}$, Maria Júlia Paes da Silva², Maria Antonieta Benko³}

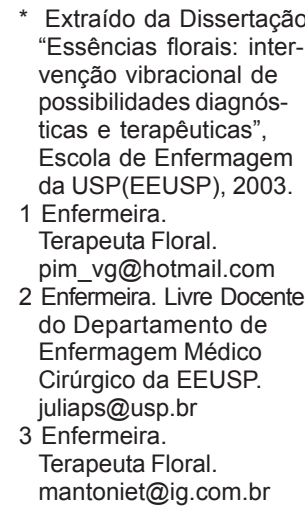

* Extraído da Dissertação "Essências florais: intervenção vibracional de possibilidades diagnósticas e terapêuticas", Escola de Enfermagem da USP(EEUSP), 2003.

1 Enfermeira. Terapeuta Floral pim_vg@hotmail.com

2 Enfermeira. Livre Docente do Departamento de Enfermagem Médico Cirúrgico da EEUSP. juliaps@usp.br

3 Enfermeira.

Terapeuta Floral. mantoniet@ig.com.br

\section{RESUMO}

Este estudo objetivou conhecer à luz da Teoria do Imaginário de Gilbert Durand, por meio do teste AT.9 e sessões de atendimento com essências florais, a eventual ação diagnóstica e terapêutica das mesmas. Realizado com 30 sujeitos, que se tratavam com as essências florais, num consultório particular na cidade de São Paulo. Os instrumentos de análise foram 60 protocolos de AT.9 preenchidos pelos 30 indivíduos em dois momentos e 60 formulações de essências florais. Analisaram-se os traços comuns, afinados e dissonantes, das relações estabelecidas entre o AT.9 e as formulações florais, trazendo evidências da sua capacidade diagnóstica e da sua ação terapêutica, com redução de oito indivíduos desestruturados para somente um. As duas essências que traduziram o tom característico dessa população foram Califórnia Wild Rose e Evening Primrose.

\section{DESCRITORES}

Medicamentos florais. Terapias complementares. Diagnóstico.

\begin{abstract}
The purpose of this study was to know the probable diagnosis and therapeutic action of the flower essences under the light of the Theory of the Imaginary by Gilbert Durand, through the AT.9 test and flower essence interview sessions. It was applied to 30 people, who were being treated with flower essences, by a private practitioner in São Paulo. The study contains 60 AT.9 test protocols and 60 flower essence formulae. It analyzed the common traces, both the attuned and the dissonant ones, by the relationships established between the AT.9 and the flower essence formulae, bringing forward evidences of the capacity diagnosis and the therapeutic actions of these essences. The two essences that translated the characteristic tone of this population were California Wild Rose and Evening Primrose.
\end{abstract}

\section{DESCRIPTORS}

Floral drugs.

Complementary therapies.

Diagnosis.

\section{RESUMEN}

Este estudo tuvo como objetivo conocer a la luz de la Teoría del Imaginario de Gilbert Durand, através del test AT.9, y sesiones de atención con esencias florales, la eventual acción diagnóstica y terapéutica de las mismas. Fue realizado con 30 sujetos, que se trataban con las esencias florales, en un consultorio particular en la ciudad de São Paulo. Los instrumentos de análisis fueron 60 protocolos de AT.9 llenados por los 30 individuos en dos momentos y 60 formulaciones de esencias florales. Se analizó los trazos comunes, afinados y disonantes, de las relaciones establecidas entre el AT.9 y las formulaciones florales, trayendo evidencias de la capacidad diagnóstica y de la acción terapéutica de las mismas, con reducción de 8 individuos desestructurados a sólo uno. Las dos esencias que tradujeron el tono característico de esa población fueron California Wild Rose y Evening Primrose.

\section{DESCRIPTORES}

Medicamentos florales. Terapias complementares. Diagnostico 


\section{INTRODUÇÃO}

Nosso interesse em estudar os temas ligados à saúde sob o prisma de um novo paradigma, no qual o ser humano é visto e compreendido em sua totalidade, vem de longa data e culmina com esta pesquisa que busca uma forma de expressar a ação das essências florais no indivíduo. Nesse caminhar foram realizados dois cursos de Especialização em Terapia Floral na Escola de Enfermagem da USP 1998 e 2000, sendo que do primeiro curso resultou o livro Florais: uma alternativa saudável ${ }^{(1)} \mathrm{com}$ a publicação dos trabalhos de pesquisa realizados nesse curso, entre outras tantas iniciativas que divulgassem essa estratégia de cuidar. Temos feito internamente muitas perguntas, algumas de fundo existencial e outras sobre a maneira de sentir o desenrolar da vida, e neste envolvimento com a terapia floral encontramos muitas respostas. Ligadas à academia foi natural procurarmos métodos que fizessem esta aproximação buscando metodologias para expressar a intervenção com a Terapia Floral, podendo ampliar e validar esta maneira de tratar a emoção humana, efetuando tradução ajustada do que é diagnosticado com instrumentos reconhecidos como o teste projetivo AT. 9 (Teste Arquétipo de 9 elementos). A fronteira que estabelecerá os padrões para estudo, uso e pesquisa com as essências florais, ainda está sendo delineada no mundo, e certamente ficará tão mais nítida, quanto mais nos utilizarmos de registros e referências que fundamentem as experiências nesta área. Porém, para não simplificar este estudo, exploramos a emoção humana, não só verificando os resultados do uso das essências florais, já evidenciados em outros estudos ${ }^{(1)}$, mas adentrando no mundo do latente, utilizando a Teoria do Imaginário de Durand.

\section{O imaginário de Gilbert Durand e o teste arquétipo de nove elementos (AT9) de Yves Durand}

O estudo se desenvolveu à luz da Teoria do Imaginário de Gilbert Durand, mais especificamente através de sua obra "As Estruturas Antropológicas do Imaginário"(2). Segundo esta teoria o imaginário é como uma rede de imagens cujo sentido dá-se pela relação estabelecida entre elas, organizando-se de acordo com uma certa lógica, com uma certa estruturação, de modo que a configuração mítica de nosso imaginário depende da forma como arrumamos nele nossas fantasias. É dessa configuração que decorre o nosso poder de melhorar o mundo, recriando-o cotidianamente, pois o imaginário é o denominador fundamental de todas as criações do pensamento humano. É um lugar de criatividade onde desenvolvem-se processos de enfrentamento do destino e onde elaboramse meios representativos, simbólicos, retóricos e racionais, de finalidade "defensiva" frente à fatalidade da morte ${ }^{(3)}$.

O imaginário pode ser considerado como um mapa com o qual lemos o mundo, pois o real decorre de uma construção simbólica. As imagens são produzidas, entre as pulsões subjetivas e as intimações do meio cósmico e social, no qual se insere a noção importantíssima do trajeto antropológico de Durand ${ }^{(2)}$, que consegue articular o biopsíquico e o sócio cultural, trajeto constante e reversivo entre as pulsões subjetivas assimiladoras (o biopsíquico) e as intimações objetivas acomodantes (do meio cósmico e sócio-cultural), de onde emergem como produto o símbolo e o imaginário.

Todas as funções da imaginação simbólica visam estabelecer, seja para o indivíduo, grupo ou cultura, uma constante reequilibração resultante da incidência desestruturadora dos fenômenos portadores da angústia original, sobre as já elaboradas produções simbólicas e imaginárias ${ }^{(2)}$. Entenda-se por equilibração antropológica de Durand, uma constante reequilibração, uma constante complexificação das produções simbólicas e imaginárias reelaboradas, e não o equilíbrio estático, filosófico, de ordem; e entendendo-se por angústia original, o enfrentamento do tempo que se esgota e, portanto, anuncia a morte.

G. Durand classificou as estruturas do imaginário em nível estritamente teórico. A validação de sua teoria coube a Yves Durand $^{(4)}$, seu discípulo, que criou um modelo normativo num teste projetivo por ele denominado AT.9 (teste arquétipo de nove elementos). Esse autor entendeu que se na concepção antropológica de G. Durand a ordem estrutural do imaginário era pertinente, também seria possível reencontrá-la em fatos relevantes da criatividade imaginária do homem comum; e o objetivo desse teste projetivo foi o de identificar os núcleos organizadores da simbolização, os universos míticos que se constituem ao longo das histórias individuais e ou grupais ${ }^{(4)}$.
Essências florais: intervenção vibraciona de possibilidades diagnósticas e terapêuticas 
Olympia Maria P. Gimenes Maria Júlia Paes da Silva Maria Antonieta Benko

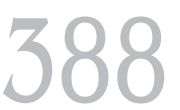

Rev Esc Enferm USP 2004; 38(4): 386-95.
Para tal investigação construiu um instrumento, composto por desenho e narrativa elaborados a partir de nove palavras chaves, a saber: queda, espada, refúgio, monstro devorante, alguma coisa cíclica, personagem, água, animal e fogo ${ }^{(4)}$. A escolha destes elementos não foi aleatória; foram considerados seus significados mais profundos, para que servissem de motivação ao sujeito, funcionando como estímulos, para fazer emergir a problemática da angústia diante do tempo mortal, e os mecanismos e meios que o sujeito encontra para enfrentar e ou resolver cada situação. Este instrumento, AT.9, compõe-se de:

1- Uma parte desenhada onde solicita-se ao sujeito que desenhe uma cena com os seguintes elementos: Uma queda, uma espada, um refúgio, um monstro devorante, alguma coisa cíclica (que gira, que se reproduz ou que progride), um personagem, água, um animal (pássaro, peixe, réptil ou mamífero) e fogo;

2 - Uma parte escrita, que chamamos de narrativa, com a instrução de escrever a história de seu desenho, contando o que se passa; e

3 - Um questionário com perguntas sobre a história, com a solicitação de responder com atenção às seguintes perguntas:
1. Qual a idéia central de sua história? Você ficou em dúvida entre duas ou mais idéias? Quais?

2. Quando você pensou em sua história, você se lembrou de algum filme ou de algum livro? Qual?

3. Indique entre os 9 elementos da sua história:a) Os elementos mais importantes do seu desenho; b) Os elementos que você gostaria de eliminar no seu desenho. Por quê?

4. Como termina a cena que você imaginou?

5. Se você tivesse que participar da cena que você compôs, quem você seria? O que você faria?

E finaliza com um quadro de simbolização (Quadro 1) para ser respondido claramente:

1. Na coluna A que desenho você fez para representar cada elemento;

2. Na coluna B qual o papel de cada elemento, para que ele serve na história;

3. Na coluna $\mathrm{C}$ o que cada elemento significa para você, qual sentido ele tem.

Quadro 1 - Simbolização dos elementos que compõem o AT.9

\begin{tabular}{|r|c|l|l|}
\hline \multirow{2}{*}{ Elemento } & A & B & C \\
\cline { 2 - 4 } & $\begin{array}{c}\text { Representado } \\
\text { por }\end{array}$ & Papel/função & Simbolizando \\
\hline Queda & & & \\
\hline Espada & & & \\
\hline Refúgio & & & \\
\hline Monstro & & & \\
\hline Alguma coisa Cíclica & & & \\
\hline Personagem & & & \\
\hline Água & & & \\
\hline Animal & & & \\
\hline Fogo & & & \\
\hline
\end{tabular}

Os nove elementos deste teste têm como alvo serem associados, sob os efeitos de uma "energia imaginária", de modo a fazer emergirem certas formas de organização (heróica, mística, sintética), um acoplamento entre os nove elementos, constituindo um "sistema" capaz de informar as estruturas imaginárias propostas, organizadas pelo sujeito ${ }^{(4)}$.
Nas soluções heróicas, a ação e a linguagem heróica dominam o conjunto da composição. Observa-se que os heróicos costumam ser pessoas mais ou menos racionais, que têm uma visão realista do mundo, da dinâmica da luta pela vida e do uso das armas de sobrevivência. Já as respostas místicas correspondem a pessoas freqüentemente 
muito imaginativas, criativas, fantasiosas e pouco agressivas com um certo gosto da intimidade secreta, uma vontade de união. Os que elaboram mecanismo sintético, podem ser definidos como pessoas criativamente inteligentes, equilibradas e capazes de buscar respostas pessoais para tudo que está ao seu redor e incide em suas vidas ${ }^{(5)}$.

Há também no AT.9, formas negativas, onde o domínio da angústia é evidente, e no extremo, ocorre o que se identifica como desestruturação de textos e desenhos, impossíveis de serem classificados por este protocolo. Nesses desenhos nomeados desestruturados, cada elemento é desenhado sem compor um conjunto, sem cenário, sem contexto; na escrita, o sujeito não constrói enredo, as frases são isoladas revelando grande dificuldade semântica. Estes desenhos desestruturados (também chamados de desenhos implodidos) e as narrativas sem enredo ou contexto, denotam alto grau de ansiedade e altíssimo nível de angústia no dia a dia.

A manifestação heróica de forma negativa demonstra, em geral, fracasso total do herói; a forma mística negativa revela geralmente o monstro possuindo a espada; já o universo sintético expressa concepções fatalistas e pessimistas da evolução humana ou de dualismo sem saída, mortífero.

Os micro universos míticos são divididos, cada qual (heróico e místico) em 4 $\operatorname{gradientes}^{(3,5-6)}$ :

- super heróico - hipervaloriza o combate onde o monstro é hiperbólico e os demais elementos são esquecidos; heróico integrado - todos os elementos concorrem para compor o cenário do combate; heróico impuro heterogeneidade onde um grupo de elementos fica como que justaposto, como "corpo estranho" evocando o universo místico, porém sem integração; heróico descontraído ou atenuado - combate poten-cializado, o herói é um herói e o monstro é um monstro; a ação é protelada e o território dividido, cada qual movendo-se na sua esfera privada.

- super místico - há escotomização do monstro e ou da espada, que desaparecem; místico integrado - monstro e espada são eufemizados pela disfuncionalização ou emblematização; místico impuro - monstro e espada disfuncionalizados, figuração arbitrária criando um "corpo estranho" heróico no cenário místico; místico lúdico - monstro e espada introduzidos num cenário de jogo, portanto integrados, sugerindo que se a ação heróica ocorrer os elementos estarão integrados.

É importante ressaltar que ciências da saúde demandam qualidade e quantidade o tempo todo, entretanto, estruturas lógicas de per si, muitas vezes não conseguem expressar a realidade. Ancoradas por estas afirmações estabelecemos laços entre o latente (simbólico) de cada criatura e o universo das essências florais, numa tentativa de transformar o abstrato em concreto, dando textura material às idéias, corporificando conceitos, fazendo corresponder símbolos às palavras e percepções, conferindo consistência ao que era pensamento.

\section{A Terapia Floral}

Falar de terapia floral é falar do caminho de Edward Bach, um caminho de iniciação de quem entrou profundamente em contato com a natureza, numa senda alquimista, para encontrar o manancial curativo latente guardado nas flores. Bach compreendeu o que já havia sido compreendido por grandes médicos como Paracelsus (1493 - 1541) e Culpeper (1616 - 1654): que a Natureza é o verdadeiro médico e que o terapeuta é apenas seu mediador ${ }^{(7)}$.

Descreveu um elo real entre emoções, somatizações e enfermidades, caminho pelo qual também se poderia estabelecer a cura. Por meio do entendimento da relação das emoções humanas com a energia das flores, estabeleceu o que chamou de um "novo sistema de cura", onde aqueles que não são médicos e nem mesmo enfermeiros, poderiam cuidar de seus semelhantes, exercendo prática simples, por meio do uso das essências florais.

Observando as flores e os estímulos que desencadeavam em si mesmo, colocou flores em recipiente com água e as expôs ao sol. Numa manhã de maio veio a grande inspiração; sol intenso e nos cálices das flores gotas brilhando como diamantes: o orvalho. Concluiu que os raios de sol transferiam o potencial das flores para a água, assim como fora no orvalho. Esse procedimento incluía os 4 elementos, a terra que sustenta a planta, o ar que nutre, o fogo que transfere força, e a água que absorve os poderes curativos e os armazena. Dr Bach descobriu assim, como transmitir as forças do macrocosmo para o microcosmo, das flores para a água ${ }^{(7)}$.
Essências florais: intervenção vibracional de possibilidades diagnósticas e terapêuticas 
Olympia Maria P. Gimenes Maria Júlia Paes da Silva Maria Antonieta Benko

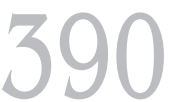

Rev Esc Enferm USP 2004; 38(4): 386-95.
Caminhando e observando optou por elaborar os "remédios" com flores frescas, colhidas no auge da florada, se possível próximo do dia de São João, quando o sol alcança toda sua força (para o hemisfério norte). Bach foi além, tomou gotas de orvalho, colocou flores na água e expôs ao sol, viveu as descobertas em seu próprio corpo experimentando sintomas emocionais e físicos. Descobriu que tomando a essência da flor os sintomas diminuíam e que a mesma essência também desencadeava alívio em padrões similares de seus pacientes. Dizia para não nos fixarmos na doença, mas para lançarmos um olhar cuidadoso em "como o paciente vê a vida" (7).

Dr. Bach, entre 1930 e 1936, preparou e classificou, 38 essências, dividindo-as em sete grupos de atuação, a saber ${ }^{(8)}$ :

- Para os que sentem medo - flores que trazem encorajamento para realizar desde as ações mais simples do cotidiano e até os enfrentamentos mais desafiantes: Rock Rose, Mimulus, Cherry Plum, Aspen, Red Chestnut;

- Para os que sofrem de indecisão - flores que trazem assertividade, clareza de propósito, vigor, esperança, otimismo e fé: Cerato, Scleranthus, Gentian, Gorse, Hornbeam, Wild Oat;

- Falta de interesse pelas circunstâncias atuais - flores que trazem presença desperta e focada no momento presente, vivificada pela alegria: Clematis, Honeysuckle, Wild Rose, Olive, White Chestnut, Mustard, Chestnut Bud;

- Para a solidão - flores que ensinam a compartilhar os próprios dons, modulando os ritmos pessoais, favorecendo os relacionamentos: Water Violet, Impatiens, Heather;

- Para os que têm sensibilidade excessiva às influências e opiniões - flores que nos ajudam a fazer transições, atuar com transparência e seguir livre de influências limitadoras: Agrimony, Centaury, Walnut, Holly;

- Para o desalento e o desespero - flores que nos ajudam a estabelecer vínculos por meio da profunda coragem da aceitação do outro e de nós mesmos: Larch, Pine, Elm, Sweet Chestnut, Star of Bethlehem, Willow, Oak, Crab Apple;

- Excessiva preocupação com o bem-estar dos outros - flores que nos ajudam a amar com compaixão, fluindo com tolerância pelo "caminho do meio": Chicory, Vervain, Vine, Beech e Rock Water (sendo esta última a única essência feita sem infusão de flor, apenas com água potencializada).

Considerava como doença real e básica do homem certos defeitos: orgulho, crueldade, ódio, egoísmo, ignorância, instabilidade e a ambição, todos contrários à unidade.

Considerava o orgulho ou arrogância como a incapacidade de reconhecer a pequenez da personalidade humana e sua absoluta dependência da Alma, e como doença, manifestando-se pela rigidez. A crueldade uma negação de que tudo está interligado, sendo a dor, o resultado deste defeito. O ódio é contrário ao Amor, portanto o reverso à lei da Criação, trazendo as conseqüências do isolamento e perturbações mentais. Assim, quando há crueldade, é preciso desenvolver a compaixão, buscando no outro e em si mesmo o bem, que existe em todos nós; o egoísmo é também a negação da Unidade, colocando interesses pessoais acima do bem estar da humanidade e conduzindo à intros-pecção e neurastenia. A cura se dá ao abrir-se para os outros, dirigindo para fora o carinho e a atenção que devotamos a nós mesmos; a ignorância é o fracasso em aprender, é a recusa em ver a verdade. Na persistência deste defeito há dificuldades de viver o cotidiano. A instabilidade, a indecisão, e a falta de determinação ocorrem quando a personalidade se recusa a ser conduzida por sua própria Alma, resultando em disfunções que afetam o movimento e a coordenação motora. É necessário desenvolver a autodeterminação, fortalecendo a mente e a ação. A ambição conduz ao desejo de poder, sendo assim, uma negação à liberdade e à individualidade. A personalidade ambiciosa dita ordens conforme sua vontade e comanda desconsiderando o outro, tendo a aprender que cada um nada mais deve fazer além de encorajar o próximo, ajudar a ter esperança, a ampliar conhecimentos e repartir experiências ${ }^{(8)}$.

Nas últimas décadas, usuários de essências florais do Dr. Bach sentiram-se impulsionados a extrair diferentes essências de flores, o que resultou em termos à disposição novos sistemas de essências florais. Os conteúdos descrevendo a ação das mesmas foram surgindo, foram aprimorados e, finalmente, publicados. Essas publicações contêm os repertórios de uso e indicação das essências 
extraídas por esses autores. São verdadeiros manuais de orientação e sugestões para os terapeutas florais utilizarem em sua prática. Os outros repertórios escolhidos como referência para este trabalho, e também seus correspondentes sistemas de essências florais, seguem a mesma compreensão de Bach sobre o uso das mesmas, e são:

- Florais da Inglaterra, essências extraídas por Julian Barnard, Healing Herbs ${ }^{\circledR}$, com a estrutura da alma humana representada nas essências de Dr. Edward Bach ${ }^{(9)}$.

- Florais da California, essências extraídas por Patrícia Kaminski e Richard Katz, Flower Essence Society ${ }^{\circledR}$, com a solar mensagem das flores nativas iluminando estados da alma do homem contemporâneo ${ }^{(9)}$.

- Florais do Alasca, essências extraídas por Steve Johnson, Alaska Project $\AA$, trazendo a força de uma natureza intocada, que se revela com essências sutis, de aceleração e freqüência altamente revitalizadora ${ }^{(10)}$.

- Florais da Austrália, essências extraídas por Ian White, Australian Bush ${ }^{\circledR}$, trazendo o vigor da tradição e do conhecimento aborígene $\mathrm{e}^{(11)}$.

- Florais da Austrália, essências extraídas por Vasudeva Barnao e Kadanbii Barnao, Living Essences ${ }^{\circledR}$, explorando a possibilidade de interagir com a vida rompendo limitações ${ }^{(12)}$.

A Terapia Floral é parte de um campo emergente de tratamentos e modalidades terapêuticas, de características não invasivas, considerada importante alavanca de cura, que amplia o universo de ações dos profissionais da saúde ${ }^{(1)}$. Cuidar, e o enfermeiro é um cuidador por excelência, com o uso das essências florais, é ir além de sintomas e queixas, é sobretudo, observar e compreender a criatura humana em sua maravilhosa complexidade.

Há várias maneiras de indicar-se as essências florais e também diferentes formas de proceder-se ao diagnóstico para a indicação das mesmas. Os métodos mais utilizados são: entrevista e aconselhamento, seguidos de indicação conforme queixas mencionadas, e seleção e indicação por meio de técnicas vibracionais, como cinesiologia (teste muscular), radiestesia (pêndulo), sensibilidade direta pelas mãos ou pela ponta dos $\operatorname{dedos}^{(9)}$.
O diagnóstico estabelecido utilizando a escolha das essências florais pela sensibilidade direta pelas pontas dos dedos, tem o tom característico da qualidade curadora das essências que compõem a formulação. Por meio de

um nível profundo e não-verbal de consciência, os métodos vibracionais podem sugerir questões e essências que estão ocultas à percepção racional; ou talvez, eles ajudem a refinar a escolha das essências após a entrevista inicial ou sessão inicial de aconselhamento ${ }^{(9)}$.

Sendo a terapia floral parte dos tratamentos vibracionais que conduzem o homem a um processo de integração entre todas as suas potencialidades e faculdades, achamos significativo revelar sua ação pautada nas evidências científicas, como neste caso, o teste arquetípico de nove elementos AT.9, buscando encontrar uma voz de expressão para pensamentos e fenômenos desconhecidos pela restrição da palavra, evidenciando, ainda, componentes desconsiderados ao pensamento constituído.

Assim, o objetivo deste estudo foi conhecer a eventual ação diagnóstica e terapêutica das essências florais à luz da Antropologia do Imaginário de Gilbert Durand.

\section{TRAJETÓRIA METODOLÓGICA}

Trata-se de um estudo prospectivo, que utilizou como instrumento de levantamento de dados, o teste de Yves Durand e a formulação de essências florais. Foi realizado num consultório particular, na cidade de São Paulo (SP) e a população foi constituída por 30 sujeitos, de ambos os sexos, com idade superior a dezoito anos, que se tratavam com as essências florais e aceitaram participar do estudo, recrutados também em outras instituições de saúde da cidade de São Paulo.

O projeto foi analisado e aprovado pelo Comitê de Ética em Pesquisa da Escola de Enfermagem da Universidade de São Paulo e os dados foram coletados, no período de março a abril de 2002. Todos os participantes assinaram o Termo de Consentimento Livre e Esclarecido, permitindo que suas respostas do AT.9 e formulações de floral fossem utilizadas para esta pesquisa. A todos foi informado o teor e a finalidade do estudo e mencionado ser livre a adesão. $\mathrm{O}$ agendamento
Essências florais: intervenção vibracional de possibilidades diagnósticas e terapêuticas 
Olympia Maria P. Gimenes Maria Júlia Paes da Silva Maria Antonieta Benko dos participantes foi efetuado, explicando-se que, imediatamente após o preenchimento do AT.9, seria efetuada a sessão para a indicação das essências florais e o atendimento ocorreu em três momentos:

Primeiro momento: aplicação do teste AT.9 - para o preenchimento do AT.9 foi assegurado ambiente calmo, sem interferências, com o conteúdo do teste impresso, lápis preto e prancheta para apoio;

Segundo momento: após cada teste foi realizada sessão terapêutica, que consta da entrevista, concomitante à passagem das pontas dos dedos sobre os frascos das essências florais. Aquelas que apresentaram, ao passar sobre elas, "formigamento", são selecionadas para compor a fórmula. Após esta seleção e indicação, é preparado o frasco contendo as essências florais selecionadas e feito o agendamento de retorno;

Terceiro momento do estudo: repetição dos $1^{\circ}$ e $2^{\circ}$ momentos (AT.9 e sessão terapêutica), com intervalo de $30-45$ dias após sua realização. Este estudo ficou constituído por sessenta AT.9 preenchidos e sessenta sessões de atendimento com as essências florais.

Ao final das duas sessões foi dado ao teste AT.9 tratamento interpretativo pela análise dos dados obtidos nos testes, com a finalidade de inventariar a estrutura dominante do imaginário dos participantes. A análise dos 60 protocolos de AT.9 foi efetuada pela educadora Livre Docente Helenir Suano, da Faculdade de Educação da Universidade de São Paulo, especialista na temática ${ }^{(6)}$. A in- dicação das essências florais nas 60 sessões realizadas foi feita pela primeira autora deste estudo; a combinação de essências florais, constituindo uma indicação diagnóstica, foi analisada e interpretada em seus significados, à luz dos repertórios publicados pelos extratores dos sistemas de essências florais utilizadas, em seus textos originais e nos seus sites oficiais, com banco de dados disponibilizados para atualização e pesquisa. Assim, neste estudo o AT.9 foi utilizado como recurso para avaliar a evolução da terapêutica com as essências florais. Não temos a pretensão, neste trabalho, de expor e discutir o AT.9 como instrumento diagnóstico na terapia floral.

\section{APRESENTAÇÃOE DISCUSSÃO DOS RESULTADOS}

Dos 30 clientes atendidos durante o trabalho, $27(90 \%)$ eram do sexo feminino e 3 $(10 \%)$ eram do sexo masculino. A idade em anos variou de 20 a 65 anos, a mediana foi de 39 anos, a média de 37,6 anos e predominou a faixa etária de 20 a 29 com 11 pessoas (36,66\%), seguida da faixa de 30 a 39 anos com 8 pessoas $(26,66 \%)$. Estas duas faixas reuniram 19 pessoas $(63,32 \%)$. Na variável escolaridade com predominância o $3^{\circ} \mathrm{Grau}$ completo, representado por 18 pessoas (60\%), seguido de 7 pessoas com o $2^{\circ} \mathrm{Grau}$ completo $(23,33 \%)$.

A Tabela 1 traz a distribuição geral dos micro universos míticos das duas aplicações do AT.9 dos 30 sujeitos da população estudada.

Tabela 1 - Distribuição da estrutura dos micro universos míticos na $1^{\mathrm{a}}$ e $2^{\mathrm{a}}$ aplicações do AT.9. (São Paulo, 2002)

\begin{tabular}{ccccc}
\hline \multirow{2}{*}{$\begin{array}{c}\text { Estruturação dos micro } \\
\text { universos míticos }\end{array}$} & \multicolumn{2}{c}{ Freqüência } & \multicolumn{2}{c}{ Porcentagem } \\
\cline { 2 - 5 } & $1^{\mathrm{a}}$ & $2^{\mathrm{a}}$ & $1^{\mathrm{a}}$ & $2^{\mathrm{a}}$ \\
\hline Heróico & 12 & 14 & 40,00 & 46,66 \\
Místico & 10 & 14 & 33,33 & 46,66 \\
Sintético & 0 & 1 & 0 & 3,33 \\
Desestruturado & 8 & 1 & 26,66 & 3,33 \\
\hline TOTAL & $\mathbf{3 0}$ & $\mathbf{3 0}$ & $\mathbf{9 9 , 9 9}$ & $\mathbf{9 9 , 9 8}$ \\
\hline
\end{tabular}

É importante notar que houve significativa redução dos indivíduos com protocolos desestruturados, do $1^{\circ}$ para o $2^{\circ}$ AT.9, demonstrando pela estruturação de textos e desenhos, a diminuição do universo de angústia, a melhora da capacidade semântica e a inserção contextualizada de conteúdos num modelo tempo/espaço. 
Os deslocamentos, ou seja, a mudança de gradiente verificada pela análise dos testes AT.9 da $1^{\text {a }}$ para a $2^{\mathrm{a}}$ aplicação, conforme as estruturações dos micro universos míticos, dos 30 sujeitos, em seus simbolismos heróicos, místicos e sintéticos, estão representados no Quadro 2.
Essências florais: intervenção vibracional de possibilidades diagnósticas e terapêuticas

Quadro 2 - Deslocamentos dos testes AT.9 da $1^{\mathrm{a}}$ para a $2^{\mathrm{a}}$ aplicação. Estruturação dos micro universos míticos. (São Paulo, 2002)

\begin{tabular}{|c|c|c|c|c|c|c|c|c|c|}
\hline \multirow[b]{2}{*}{ Prot." } & \multicolumn{4}{|c|}{ Heróico } & \multirow{2}{*}{$\begin{array}{c}\text { Sintético } \\
\begin{array}{c}\text { Duplo universo } \\
\text { existencial }\end{array}\end{array}$} & \multicolumn{4}{|c|}{ Místico } \\
\hline & $\begin{array}{c}\text { Super } \\
\text { Heróico }\end{array}$ & $\begin{array}{c}\text { Heróico } \\
\text { Integrado }\end{array}$ & $\begin{array}{r}\text { Heróico } \\
\text { impuro }\end{array}$ & $\begin{array}{c}\text { Heróico } \\
\text { descontraído }\end{array}$ & & $\begin{array}{l}\text { Místico } \\
\text { Lúdico }\end{array}$ & $\begin{array}{l}\text { Místico } \\
\text { Impuro }\end{array}$ & $\begin{array}{c}\text { Místico } \\
\text { Integrado }\end{array}$ & $\begin{array}{c}\text { Super } \\
\text { Místico }\end{array}$ \\
\hline 01 & & & & & & 4 & 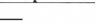 & & \\
\hline 02 & & & & & & & & $\longleftrightarrow$ & \\
\hline 03 & & & & & & & & $\hbar$ & \\
\hline 04 & & & & & & & 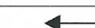 & 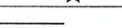 & \\
\hline $05 \star$ & & & & & & & & & \\
\hline 06 & & $\hbar$ & & & & & & & \\
\hline 07 & & & & $\longleftrightarrow$ & & & & & \\
\hline 08 & & & & & & & $\rightarrow$ & & \\
\hline 09 & & & & $t$ & & & & & \\
\hline 10 & & & & & & & $\hbar$ & & \\
\hline 11 & & & 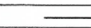 & & & & $\rightarrow$ & & \\
\hline 12 & & & & & & & & $\longleftrightarrow$ & \\
\hline 13 & & & $\hookrightarrow$ & & & & & & \\
\hline 14 & & & & $\longrightarrow$ & & & & & \\
\hline 15 & & & & $t$ & & & & & \\
\hline${ }^{16} t$ & & & & & & & & & \\
\hline 17 & & & & 4 & & & - & & \\
\hline 18 & & 4 & & & & & - & & \\
\hline 19 & & & & & & & $t$ & & \\
\hline 20 & & & & $\leftrightarrow$ & & & & & \\
\hline 21 & & & & & & & & $\longleftrightarrow$ & \\
\hline 22 & & & $\hookrightarrow$ & & & & & & \\
\hline 23 & & & & & 4 & & & E & \\
\hline 24 & & & & & & & $\longleftrightarrow$ & & \\
\hline 25 & & & & $\longrightarrow$ & & & & & \\
\hline 26 & & & & & & & 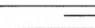 & $\Rightarrow$ & \\
\hline 27 & & & & & & & $\rightarrow$ & & \\
\hline 28 & & & & & & & $\Rightarrow$ & & \\
\hline 29 & & $\longrightarrow$ & & & & & & & \\
\hline 30 & & & & $\Rightarrow$ & & & & & \\
\hline
\end{tabular}

É relevante a cuidadosa observação do Quadro 2 em seus deslocamentos, conforme inventário do teste AT.9, especialmente porque, o diagnóstico em terapia floral incide sobre a perspectiva de nos deslocarmos constantemente entre os aspectos emocionais negativos e os positivos, como um processo alquímico da "união dos opostos", processo natural de re-equilibração psíquica. O diagnóstico realizado com as essências florais não define padrões de normalidade e suas variações; traduz padrões de significado e suas expressões, sendo feito sobre o ser, sobre a criatura, abrangendo um momento emocional, no contexto dinâmico da biografia humana.

Não há expectativa de proceder-se à exatidão diagnóstica, visto não haver padrões exemplares previamente estabelecidos. Todavia, a validação diagnóstica pode ser verificada se analisarmos o processo de equilíbrio, como um todo, abrangendo desde mudanças nos patternings of behavoir (padrões de comportamento), até ao reconhecimento pelo próprio sujeito do alívio de sintomas, confiança na vida, evidências de bem estar e ou entendimento do próprio processo e reconfiguração de seu destino.
Estabelecer um diagnóstico com as essências florais não se restringe a acertar ou errar na indicação; é algo como observar alguém nadando em alto mar; numa primeira impressão, não saberemos se trata-se de um afogamento ou de nado em mar aberto; a observação e o seguimento do evento trazem a resposta. Para melhor entendimento do Quadro 2, em seus deslocamentos, é importante considerar que a convergência dos protocolos de estruturação heróica e de estruturação mística, em direção à estruturação de simbolismo sintético, conforme referência anterior, indica maiores possibilidades adaptativas dos indivíduos, visto ser na estrutura sintética que o místico e o heróico se encontram de modo conjunto, uma dupla atualização mítica da ansiedade, como que uma conciliação dos contrários.

$\mathrm{Na}$ análise dos deslocamentos do $1^{\circ}$ AT.9 para o $2^{\circ}$ AT.9 agrupamos os protocolos em:

Forma negativa com deslocamento para o positivo -pudemos perceber que em quatro protocolos houve incidência de estruturação de forma negativa, ou seja, o monstro portando a espada, o fracasso ou fuga do herói. Em dois deles houve reversão deste quadro; Sem mudança de gradiente 
Olympia Maria P. Gimenes Maria Júlia Paes da Silva Maria Antonieta Benko

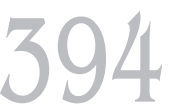

Rev Esc Enferm USP 2004; 38(4): 386-95. na estruturação do AT.9 -em 9 indivíduos (protocolos $\left.{ }^{\text {os }} 2,7,12,13,20,21,22,24,29\right)$, não houve deslocamento do $1^{\circ}$ AT.9 para o $2^{\circ}$ AT.9 , quanto à estruturação heróica, mística e sintética. $\mathrm{Na}$ análise dos dois AT.9 notou-se que mesmo sem mudança de gradiente ocorreu perlaboração de conteúdo, comprovada pela mudança de registro das imagens. Destes, 8 sujeitos faziam uso das essências florais dentro de um processo terapêutico, com regularidade, sendo atendidos em programas de tratamento, por um terapeuta floral. Os deslocamentos na estruturação do AT.9 expressaram o movimento energético presente no imaginário dos sujeitos e indicaram a dinâmica da psique, onde a mudança da imagem leva à mudança de comportamento e evidências da perlaboração; Desestruturado com mudança de gradiente-de 9 indivíduos com protocolos desestruturados no $1^{\circ}$ AT.9 $\left(\mathrm{n}^{\text {os }} 3,5,6,9,10\right.$, $15,16,19) 8$ indivíduos se estruturaram em algum gradiente dos universos míticos e, somente o indivíduo do protocolo $\mathrm{n}^{\circ} 16$, manteve-se desestruturado no desenho e narrativa; Estruturado com mudança de gradiente - de 13 indivíduos dos protocolos com mudança de gradiente, em 12 houve deslocamento em direção à estruturação sintética $\left(\mathrm{n}^{\mathrm{os}} 1,4,8,11\right.$, $14,17,18,23,25,26,27,28,30$ ) evidenciando melhores possibilidades adaptativas para exercer mecanismos de enfrentamento do cotidiano. Em apenas um indivíduo, de protocolo $\mathrm{n}^{\circ}$ 26 , ocorreu o que nomeamos de deslocamento não esperado, ou seja, aquele que distancia o gradiente ini-cial do $1^{\circ}$ para o $2^{\circ}$ AT.9 da estrutura de simbolização sintética.

Comparando o $1^{\circ}$ e $2^{\circ}$ AT.9, chamou-nos a atenção, a mudança de 8 indivíduos com protocolos desestruturados no primeiro momento, para apenas um após a segunda aplicação, evidenciando significativa redução do universo de angústia, e apontando para os florais como agentes dessa ação.

Em 12 indivíduos (40\%) houve mudança de gradiente quanto à estruturação heróica, mística e/ou sintética, indicando perlaboração; em onze deles $(36,66 \%)$ o deslocamento foi notado em direção à estruturação sintética, denotando movimento da imaginação criadora em sua capacidade de produzir novas realidades. A qualidade da mudança, em seu simbolismo nas imagens, tem semelhança com a qualidade curadora das essências florais indicadas.

Em 9 indivíduos (30\%) não ocorreu deslocamento de gradiente quanto à estruturação heróica, mística e sintética; a mudança foi constatada na qualidade da elaboração traduzida nos textos e quadro de simbolização dos AT.9; e a perlaboração confirmou-se pela mudança de registro das imagens do $1^{\circ}$ para o $2^{\circ}$ AT.9, tendo sua expressão condizente com o significado das essências florais indicadas.

Duas essências florais traduziram o tom característico dessa população nas 60 sessões de atendimento: California Wild Rose e Evening Primrose, expressando, respectivamente, a qualidade de manifestar amor à vida $\mathrm{e}$ a capacidade de comprometimento e vínculo.

\section{CONSIDERAÇÕES FINAIS}

Os deslocamentos observados dos gradientes ajudaram a visualizar e compreender o processo de cada sujeito e o movimento interno das elaborações; o AT.9 revelou-se instrumento de confirmação diagnóstica das essências florais, ao inventariar desestruturações e estruturações negativas, situações de alto nível de angústia, para as quais essências com a expressão curadora desse padrão haviam sido indicadas.

Entendemos que o AT.9 trouxe visibilidade, num paralelismo nítido, à ação das essências florais, um revelando o outro, complementando-se sem fusão, delineando evidências; o AT.9 como que desnuda o simbólico e o corporifica; incorporado à terapia floral, faz o mesmo pelo inverso, corporifica as emoções em seus gradientes e depois desnuda a ação das essências florais em seus efeitos.

Consideramos que será benéfica a utilização do AT.9 na terapia floral, com clientes na primeira consulta, visto obter-se por meio dele, registros de sensibilidade profunda, dados que normalmente não aparecem na entrevista e também poderá auxiliar o terapeuta floral, pela observação dos gradientes, a proceder encaminhamentos para outros profissionais ou práticas complementares, conforme a gravidade do caso.

Acreditamos que com esses dois recursos - terapia floral e imaginário - amplia-se nossa capacidade de compreender o ser / estar humano, pois é construída como que uma linha de sutura invisível, energética, inclusiva, complexa, sensível, facilitando o entendimento e encurtando as distâncias na busca da autonomia. 
Lamentavelmente, não cabe neste estudo apreciar todas as relações estabelecidas entre os sessenta AT.9 e as sessenta formulações com as essências florais; tendo ficado, entretanto, clara a riqueza de recursos que o AT.9 (como instrumento), e as essências florais (como intervenção), podem articular e permear, na facilitação dos processos individuais de perlaboração, crescimento e evolução, respeitando a criatura humana em sua individualidade, complexidade e desenvolvimento.
Há evidências e há relativismos. Na grande aventura do conhecimento humano, que seja este estudo um passo alfa, uma ponte que permita a eventual passagem do real ao simbólico, numa viagem preliminar plena, onde o tempo e o entendimento sejam a própria ponte, construída da mesma massa, sob o mesmo código, permitindo a passagem do ser aos domínios do absoluto, sem qualquer grandeza, senão a de um ponto inicial.

\section{REFERÊNCIAS}

(1) Silva MJP, Gimenes OMP, coordenadoras. Florais: uma alternativa saudável: pesquisas revelam tratamentos e resultados dessa terapia. São Paulo: Gente; 1999.

(2) Durand G. As estruturas antropológicas do imaginário: introdução à arquetipologia geral. Trad. de Hélder Godinho. $2^{\mathrm{a}}$ ed. São Paulo: Martins Fontes; 2001.

(3) Teixeira MCS. Imaginário, cultura e educação: um estudo sócio-antropológico de alunos de escolas de $1^{\circ}$ grau. [livre-docência] São Paulo (SP): Faculdade de Educação da USP; 1994.

(4) Durand Y. A formulação experimental do imaginário e seus modelos. Rev Fac Educ 1987; 13(2):133-54.

(5) Badia DD. Imaginário e ação cultural. Londrina: UEL; 1999.

(6) Suano H. Cultura e imaginário sócioorganizacional um estudo sócio-antropológico no universo de uma organização educativa. [tese] São Paulo (SP): Faculdade de Educação da USP; 1993.
(7) Scheffer M, Storl WD. Flores que curan el alma: uma nueva visión de la terapia floral de Bach. Espana: Urano; [s.d.].

(8) Bach E. Os remédios florais do Dr Bach. Trad. de Alípio Correa de França Neto. São Paulo: Pensamento; 1995.

(9) Kaminski P, Katz R. Repertório das essências florais: um guia das essências norte-americanas e inglesas para o bem estar emocional/espiritual. São Paulo: Triom; 1997.

(10) Johnson S. A essência da cura: um guia das essências do Alasca. São Paulo: Triom; 2001.

(11) White I. Essências florais Australianas. Trad. de Ruth Lenz César. $2^{a}$ ed. São Paulo: Triom; 1994.

(12) Barnao V, Barnao K. Essências florais Australianas para o século XXI: living essences. São Paulo: Triom; 2000.
Essências florais: intervenção vibracional de possibilidades diagnósticas e terapêuticas
Correspondência para: Olympia Maria P. Gimenes R. Raul Pompéia, 726 Ap. 163 - Pompéia -

São Paulo

CEP - 05025-010 - SP 